\title{
Exhaled nitric oxide in 4-year-old children: relationship with asthma and atopy
}

\section{To the Editors:}

The paper by BRUSSEE et al. [1] describes the first large survey of the fraction of exhaled nitric oxide $(F \mathrm{eNO})$ in a young population. The authors should be congratulated for undertaking such a study in an age range where great patience and persistence are required to obtain data.

BRUSSEE et al. [1] reported only a marginal increase in FeNO among atopic and asthmatic children compared with the nonatopic nonasthmatic children studied. One explanation for the large overlap in the distribution of $F$ eNO in children with and without asthma or atopy could be that, at this age, the difference is simply smaller than in older children. There are three methodological issues that may have reduced the ability of the study to detect differences in FeNO between groups, and I would be grateful if the authors would clarify these issues.

First, in the study, the mean FeNO from two exhaled breath samples was reported, unless the individual values varied by $>10 \mathrm{ppb}$. Current guidelines recommend that paired online $\mathrm{FeNO}$ values should be within $5 \%$ of each other [2], but these criteria may be too stringent in young children whose FeNO values are low relative to older children. How did the authors determine the criteria for their recent study [1]? As the difference between paired values increases, the criteria used in this study will result in FeNO reflecting allergic airway inflammation less accurately; for example, paired values of $4 \mathrm{ppb}$ ("low") and $12 \mathrm{ppb}$ ("high") would be reported as $8 \mathrm{ppb}$ ("average"), but which, if either, value was "correct"? If stricter criteria were applied (for example, only considering paired measurements within $5 \mathrm{ppb}$ of each other), were $\mathrm{FeNO}$ values more discriminating between atopic and nonatopic children, even though fewer data points are analysed?

Secondly, this group has previously reported that paired measurements using this technique were within the limits of agreement [3]. Did the authors also find good reproducibility between the paired FeNO values in the study of 4-yr-old children [1]? Finally, the authors have previously reported [2] that ambient nitric oxide of $<20 \mathrm{ppb}$ influenced the $F \mathrm{eNO}$ values using the apparatus from the recent study [1]. I note that in the recent study, children inhaled through a charcoal nitric oxide filter, and that measurements were not taken on days when ambient nitric oxide exceeded $20 \mathrm{ppb}$. The authors report that, when analyses were limited to children where ambient nitric oxide levels were $<10 \mathrm{ppb}$ at the time of testing, similar results to the whole population were obtained [1].

Thus, ambient nitric oxide does not appear to have substantially influenced the relationship between the fraction of exhaled nitric oxide and asthma/atopy, but I would appreciate it if the authors could clarify whether ambient nitric oxide influenced the fraction of exhaled nitric oxide.

\section{S.W. Turner}

Senior Lecturer in Child Health, University of Aberdeen, Royal Aberdeen Children's Hospital, Aberdeen, UK.

\section{REFERENCES}

1 Brussee JE, Smit HA, Kerkhof M, et al. Exhaled nitric oxide in 4-year-old children: relationship with asthma and atopy. Eur Respir J 2005; 25: 455-461.

2 Baraldi E, de Jongste JC, Force ET. Measurements of exhaled nitric oxide in children. Eur Respir J 2001; 20: 223-237.

3 Pijnenburg MW, Lissenberg ET, Hofhuis W, et al. Exhaled nitric oxide measurements with dynamic flow restriction in children aged 4-8 yrs. Eur Respir J 2002; 20: 919-924.

DOI: 10.1183/09031936.05.00035705

From the authors:

We would like to thank S. Turner for his interest in our work, and we are pleased to comment on the methodological issues raised.

The first issue deals with the reproducibility of the fraction of exhaled nitric oxide $(F \mathrm{eNO})$ measurement within a child. In our study [1], we observed a good correlation between the first and the second $F$ eNO measurements from the children (Spearman $\mathrm{r}=0.73 ; \mathrm{p}<0.001)$. Also, in the majority of the children, the mean difference between the duplicate FeNO measurements was $<5 \mathrm{ppb}(89 \%)$, whereas, in a small minority of children, the difference was $>10 \mathrm{ppb}(2 \%$; fig. 1). To find a reasonable balance between the reproducibility of the measurement on the one hand, and the maintenance of sufficient numbers of children on the other hand, we chose to include all children for whom the difference between the duplicate FeNO measurements was within $10 \mathrm{ppb}$. Separate analyses of children for whom the duplicate measurements were within $5 \mathrm{ppb}$ produced similar results. For example, in the total study population, the geometric mean $\mathrm{FeNO}$ values in ppb (95\% confidence interval) for children with and without a doctor's diagnosis of asthma were $9.4(7.6-11.7)$ and $7.6(7.3-8.0)$, respectively $(p=0.06)$, instead of $10.0(8.3-12.1)$ and 7.9 (7.5-8.2), respectively $(\mathrm{p}<0.05)$, when duplicate samples were within $10 \mathrm{ppb}$ from each other. With respect to atopy, these numbers were 9.1 $(8.0-10.4)$ and $7.4(7.0-7.9)$, respectively $(p<0.05)$, for samples within $5 \mathrm{ppb}$, and $9.4(8.4-10.5)$ and $7.7(7.2-8.1)$, respectively $(\mathrm{p}<0.05)$, for samples within $10 \mathrm{ppb}$. So, when more stringent 